\title{
Progression from colorectal adenoma to carcinoma is associated with non-random chromosomal gains as detected by comparative genomic hybridisation
}

\author{
Gerrit A Meijer, Mario A J A Hermsen, Jan P A Baak, Paul J van Diest, \\ Stefan G M Meuwissen, Jeroen A M Beliën, Jan M N Hoovers, Hans Joenje, \\ Peter J F Snijders, Jan M M Walboomers
}

Vrije Universiteit,

Amsterdam,

The Netherlands:

Department of

Pathology, Academisch

Ziekenhuis

G A Meijer

M A J A Hermsen

J P A Baak

$\mathrm{P} J$ van Diest

J A $M$ Beliën

P J F Snijders

J M M Walboomers

Department of

Gastroenterology,

Academisch

Ziekenhuis

S G M Meuwissen

Department of Human

Genetics

H Joenje

Academic Medical

Centre, Amsterdam,

The Netherlands:

Institute of Human

Genetics

J M N Hoovers

Correspondence to:

Professor Dr J P A Baak,

Department of Pathology,

Academisch Ziekenhuis Vrije

Universiteit, PO Box 7057

1007 MB Amsterdam,

The Netherlands;

email: pathol@azvu.nl

Accepted for publication

22 July 1998

\begin{abstract}
Aims-Chromosomal gains and losses were surveyed by comparative genomic hybridisation (CGH) in a series of colorectal adenomas and carcinomas, in search of high risk genomic changes involved in colorectal carcinogenesis.
\end{abstract}

Methods-Nine colorectal adenomas and 14 carcinomas were analysed by $\mathrm{CGH}$, and DNA ploidy was assessed with both flow and image cytometry.

Results-In the nine adenomas analysed, an average of 6.6 (range 1 to 11) chromosomal aberrations were identified. In the 14 carcinomas an average of 11.9 (range 5 to 17) events were found per tumour. In the adenomas the number of gains and losses was in balance $(3.6 v 3.0)$ while in carcinomas gains occurred more often than losses $(8.2 v 3.7)$. Frequent gains involved $13 q, 7 p, 7 q, 8 q$, and $20 q$, whereas losses most often occurred at $18 q, 4 q$, and $8 p$. Gains of $13 q, 8 q$, and $20 q$, and loss of $18 \mathrm{q}$ occurred more often in carcinomas than in adenomas $(p=0.005, p=0.05$, $\mathrm{p}=0.05$, and $\mathrm{p}=0.02$, respectively). Aneuploid tumours showed more gains than losses (mean $9.3 v 4.9, \mathrm{p}=0.02$ ), in contrast to diploid tumours where gains and losses were nearly balanced (mean 3.1 $v 4.1, \mathrm{p}=0.5)$.

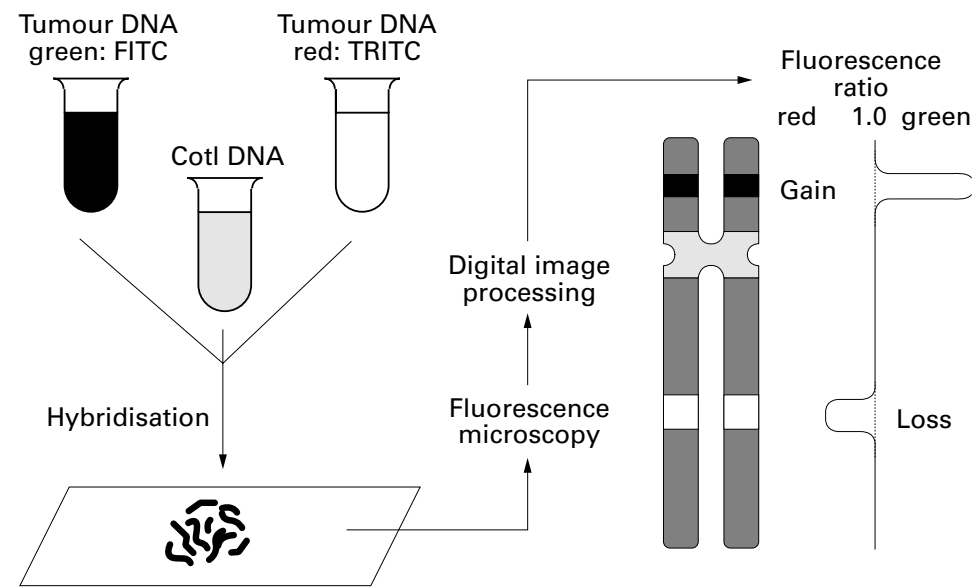

Normal human metaphase

Figure 1 Schematic overview of the comparative genomic hybridisation (CGH) technique. Tumour and reference DNA are labelled with a green and red fluorochrome, respectively, and hybridised to normal metaphase spreads. Images of the fluorescent signals are captured and the green to red signal ratios are digitally quantified along the chromosomal axis for each chromosome. (Reprinted with permission from Hermsen et al, Human Pathology 1996;27:342-9.)
Conclusions-The most striking difference between chromosomal aberrations in colorectal adenomas and carcinomas, as detected by CGH, is an increased number of chromosomal gains that show a nonrandom distribution. Gains of $13 q$ and also of $20 \mathrm{q}$ and $8 \mathrm{q}$ seem especially to be involved in the progression of adenomas to carcinomas, possibly owing to low level overexpression of oncogenes at these loci. (f Clin Pathol 1998;51:901-909)

Keywords: colon; tumour; comparative genomic hybridisation

Colorectal cancer is the second leading cause of cancer death in the Western world. Intensive scientific efforts have been made attempting to resolve the genetic changes underlying colorectal cancer. ${ }^{1}$ Nevertheless, these changes are still not completely understood. Progress in this area would, however, benefit strategies for both primary and secondary prevention of colorectal cancer. In addition, analysis of genetic changes in cancers is becoming increasingly important for both classification and prognosis assessment.

Because of the research methods availableincluding mutation analysis and polymerase chain reaction (PCR) based loss of heterozygosity analysis - most attention in the past decade has focused on genetic changes at the subchromosomal level, such as mutations and deletions leading to inactivation of tumour suppressor genes. More recently there has been a reappraisal of changes at the chromosomal level. This reappraisal is a result of the growing awareness that lack of genome integrity, or genomic instability, is in itself a hallmark of the development and progression of neoplasia. However, the term genomic instability is ill defined and may refer to inherently different features such as aneuploidy, microsatellite instability, or p53 mutation.

We would like to adopt the definition of genomic instability as a cellular state characterised by a deficiency in one or more "caretaker" genes, as a result of which structural and numerical genomic alterations accumulate in subsequent generations of daughter cells. Some of these changes may affect genes that play a key role in critical pathways controlling, for example, proliferation or apoptosis"gatekeeper" genes. ${ }^{2}$ Two major patterns of genomic instability have recently been described to fit this definition ${ }^{3}$ : first, instability caused by failing DNA repair at the nucleotide level, as 
A
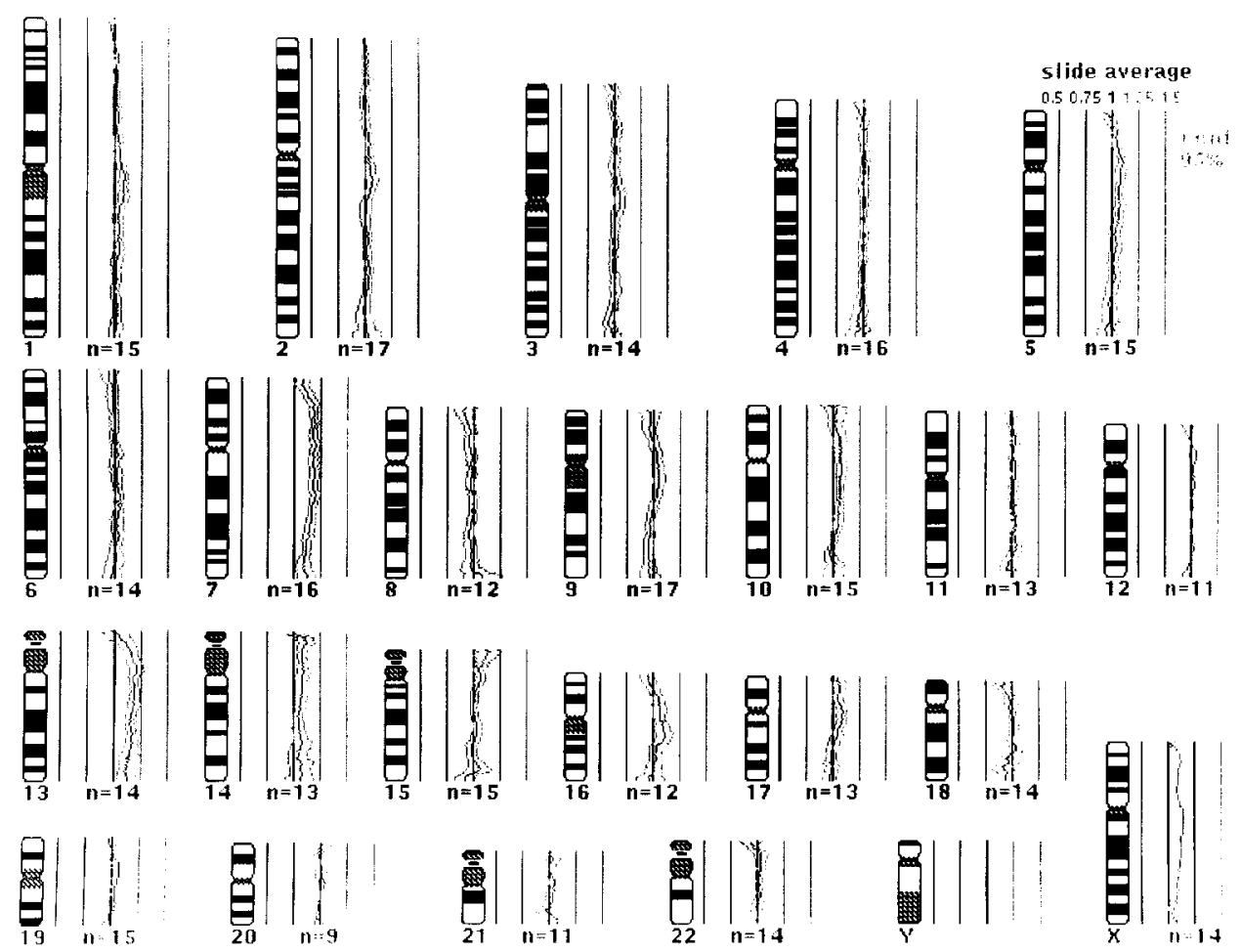

B
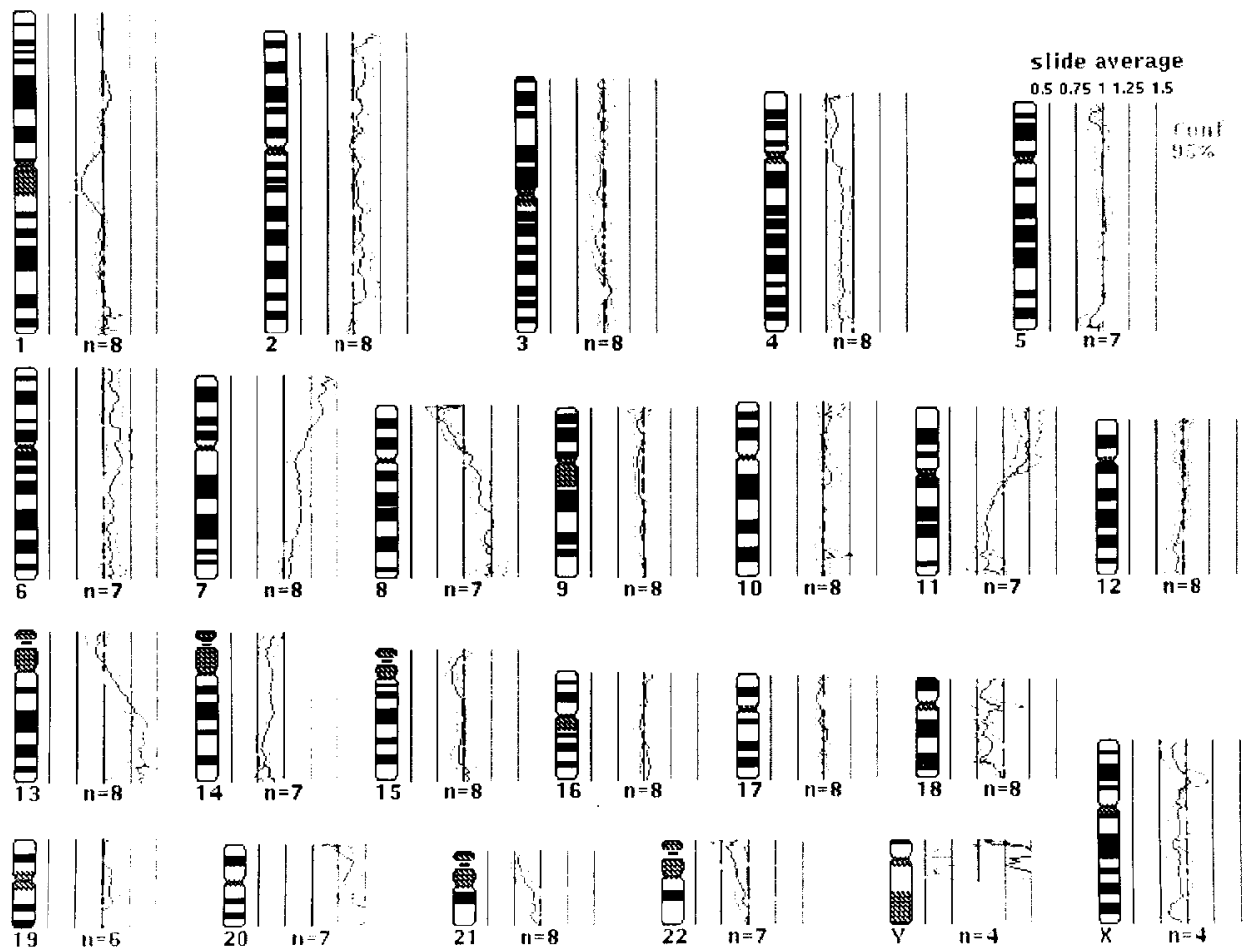

Figure 2 Relative copy number karyotypes of a colorectal adenoma $(A)$ and carcinoma (B) showing a graphical display of the mean and $95 \%$ confidence interval of the green to red fluorescence ratio along all individual chromosomes, obtained by analysing multiple metaphases. When at a locus the complete $95 \%$ confidence interval (CI) of the mean fluorescence ratio is right of the 1.0 line this is interpreted as a gain. On the other hand, when the complete $95 \%$ CI is left of the 1.0 line, this is regarded as a loss. The adenoma $(A$, case 7$)$ shows gains at $5 p, 5 q, 7 p, 7 q, 10 q$, and $13 q$. The fuorescence ratio for chromosome $X$ is smaller than 1.0 because male tumour DNA was compared to female normal $D N A$. In the carcinoma (B, case 14), clear gains can be seen for $7 p, 7 q, 8 q, 11 p, 13 q, 20 p$, and 20q, and losses for $4 p$, 4q, $8 p, 11 q, 14 q, 18 p$, and $18 q$. Smaller aberrations are seen at 5q, 6p, and $6 q$. 
Table 1 Summary of clinical and pathological data, DNA ploidy, and CGH results in nine colorectal adenomas and 14 carcinomas

\begin{tabular}{|c|c|c|c|c|c|c|c|c|c|c|}
\hline Tumour & $\begin{array}{l}\text { Age } \\
\text { (years) }\end{array}$ & $\operatorname{Sex}$ & Site & $\begin{array}{l}\text { Histological } \\
\text { type }\end{array}$ & $\begin{array}{l}\text { Grade of } \\
\text { dysplasia }\end{array}$ & $\begin{array}{l}\text { Size } \\
(\mathrm{mm})\end{array}$ & $\begin{array}{l}D N A \\
\text { index }\end{array}$ & Gains & Losses & Events \\
\hline 1 & 66 & $\mathrm{~F}$ & Sigmoid & $\mathrm{T}$ & Mild & 11 & 1.0 & $18 \mathrm{q}, 20 \mathrm{q}$ & $2 \mathrm{p}, 2 \mathrm{q}, 7 \mathrm{q}, 14 \mathrm{q}$ & 6 \\
\hline 2 & 67 & M & Sigmoid & $\mathrm{V}$ & Moderate & 20 & 1.0 & $1 \mathrm{p}, 1 \mathrm{q}, 6 \mathrm{q}, 7 \mathrm{p}, 12 \mathrm{q}, 19 \mathrm{p}, 19 \mathrm{q}$ & $9 \mathrm{p}, 9 \mathrm{q}, \mathrm{Xp}, \mathrm{Xq}$ & 11 \\
\hline 3 & 69 & $\mathrm{~F}$ & Rectum & $\mathrm{V}$ & Moderate & 10 & 1.0 & $2 \mathrm{p}, 2 \mathrm{q}, 4 \mathrm{q}, 5 \mathrm{q}, 13 \mathrm{q}$ & $17 p, 20 p$ & 7 \\
\hline 4 & 48 & $\mathrm{~F}$ & Sigmoid & $\mathrm{T}$ & Moderate & 3 & 1.0 & $6 \mathrm{q}, 15 \mathrm{q}$ & $10 \mathrm{p}$ & 3 \\
\hline 5 & 84 & $\mathrm{~F}$ & Sigmoid & $\mathrm{T}$ & Moderate & 10 & 1.0 & $3 \mathrm{q}, 7 \mathrm{p}, 7 \mathrm{q}, 8 \mathrm{q}, 10 \mathrm{q}, 20 \mathrm{q}$ & $10 p, 10 q, 16 p, 19 p, 19 q$ & 11 \\
\hline 6 & 66 & M & Transverse & $\mathrm{T}$ & Moderate & 9 & 1.0 & - & $7 \mathrm{q}$ & 1 \\
\hline 7 & 66 & M & Ascending & $\mathrm{T}$ & Mild & 5 & 1.0 & $5 \mathrm{p}, 5 \mathrm{q}, 7 \mathrm{p}, 7 \mathrm{q}, 10 \mathrm{q}, 13 \mathrm{q}$ & - & 6 \\
\hline 8 & 66 & M & Transverse & $\mathrm{T}$ & Mild & 6 & 1.0 & $5 \mathrm{q}, 7 \mathrm{p}, 7 \mathrm{q}$ & $5 q, 22 q$ & 5 \\
\hline 9 & 83 & M & Caecum & $\mathrm{T}$ & Moderate & 5 & 1.0 & $8 \mathrm{q}$ & $1 \mathrm{p}, 2 \mathrm{q}, 9 \mathrm{q}, 10 \mathrm{q}, 11 \mathrm{q}, 12 \mathrm{q}, 17 \mathrm{q}, 20 \mathrm{q}$ & 9 \\
\hline 10 & 72 & $\mathrm{~F}$ & Rectum & B2 & Moderate & 47 & 1.6 & $\begin{array}{l}6 \mathrm{p}, 6 \mathrm{q}, 7 \mathrm{p}, 9 \mathrm{p}, 9 \mathrm{q}, 10 \mathrm{q}, 11 \mathrm{p} \\
12 \mathrm{p}, 12 \mathrm{q}, 13 \mathrm{q}, 20 \mathrm{p}, 20 \mathrm{q}\end{array}$ & $22 \mathrm{q}$ & 13 \\
\hline 11 & 29 & $\mathrm{~F}$ & Rectum & B2 & Poor & 40 & 1.0 & $4 \mathrm{q}, 5 \mathrm{q}, 6 \mathrm{p}, 6 \mathrm{q}, 8 \mathrm{q}, 13 \mathrm{q}, 18 \mathrm{q}$ & $22 \mathrm{q}$ & 8 \\
\hline 12 & 57 & $\mathrm{~F}$ & Rectum & $\mathrm{C} 2$ & Moderate & 55 & 1.0 & $1 \mathrm{q}, 7 \mathrm{p}, 7 \mathrm{q}, 13 \mathrm{q}, 20 \mathrm{p}, 20 \mathrm{q}$ & $2 \mathrm{q}, 4 \mathrm{q}$ & 8 \\
\hline 13 & 66 & $\mathrm{~F}$ & Sigmoid & $\mathrm{C} 2$ & Moderate & 55 & 1.7 & $8 \mathrm{q}, 13 \mathrm{q}$ & $4 \mathrm{q}, 5 \mathrm{p}, 6 \mathrm{q}, 10 \mathrm{q}, 14 \mathrm{q}, 16 \mathrm{q}$ & 8 \\
\hline 14 & 67 & M & Sigmoid & B1 & Moderate & 40 & 1.8 & $\begin{array}{l}6 \mathrm{p}, 6 \mathrm{q}, 7 \mathrm{p}, 7 \mathrm{q}, 8 \mathrm{q}, 11 \mathrm{p}, 13 \mathrm{q} \\
20 \mathrm{p}, 20 \mathrm{q}\end{array}$ & $4 \mathrm{p}, 4 \mathrm{q}, 5 \mathrm{q}, 8 \mathrm{p}, 11 \mathrm{q}, 14 \mathrm{q}, 18 \mathrm{p}, 18 \mathrm{q}$ & 17 \\
\hline 15 & 80 & $\mathrm{~F}$ & Sigmoid & $\mathrm{C} 2$ & Moderate & 80 & 1.2 & $1 \mathrm{q}, 7 \mathrm{p}, 7 \mathrm{q}, 13 \mathrm{q}$ & $22 \mathrm{q}$ & 5 \\
\hline 16 & 47 & M & Rectum & B1 & Moderate & 20 & 1.0 & $4 q, 5 q, 7 q, 9 q, 10 q, 13 q$ & $6 \mathrm{p}, 21 \mathrm{q}, \mathrm{Xq}$ & 9 \\
\hline 17 & 65 & M & Rectum & $\mathrm{C} 2$ & Moderate & 60 & 1.4 & $\begin{array}{l}7 \mathrm{p}, 7 \mathrm{q}, 8 \mathrm{q}, 9 \mathrm{p}, 9 \mathrm{q}, 12 \mathrm{q}, 13 \mathrm{q} \\
16 \mathrm{p}, 20 \mathrm{q}\end{array}$ & $3 \mathrm{q}, 8 \mathrm{p}, 17 \mathrm{p}, 18 \mathrm{p}, 18 \mathrm{q}, 19 \mathrm{p}, 21 \mathrm{q}$ & 16 \\
\hline 18 & 67 & $\mathrm{~F}$ & Caecum & $\mathrm{D}$ & Moderate & 50 & 1.5 & $\begin{array}{l}2 \mathrm{p}, 2 \mathrm{q}, 3 \mathrm{q}, 7 \mathrm{p}, 7 \mathrm{q}, 8 \mathrm{q}, 9 \mathrm{p}, 9 \mathrm{q} \\
11 \mathrm{q}, 13 \mathrm{q}, 20 \mathrm{q}\end{array}$ & $1 \mathrm{q}, 12 \mathrm{p}, 18 \mathrm{q}$ & 14 \\
\hline 19 & 58 & M & Caecum & $\mathrm{C} 2$ & Moderate & 90 & 2.0 & $\begin{array}{l}1 \mathrm{p}, 1 \mathrm{q}, 2 \mathrm{q}, 4 \mathrm{q}, 6 \mathrm{p}, 6 \mathrm{q}, 7 \mathrm{p}, 7 \mathrm{q} \\
8 \mathrm{q}, 11 \mathrm{q}, 14 \mathrm{q}, 16 \mathrm{p}, 16 \mathrm{q}, 17 \mathrm{q} \\
20 \mathrm{q}, \mathrm{X}^{-}\end{array}$ & $6 \mathrm{q}$ & 17 \\
\hline 20 & 80 & $\mathrm{~F}$ & Rectum & $\mathrm{C} 2$ & Moderate & 35 & 1.0 & $7 \mathrm{p}, 7 \mathrm{q}, 8 \mathrm{q}, 13 \mathrm{q}, 20 \mathrm{p}, 20 \mathrm{q}$ & $15 \mathrm{q}, 17 \mathrm{p}, 18 \mathrm{p}, 18 \mathrm{q}, \mathrm{Xq}$ & 11 \\
\hline 21 & 63 & M & Liver & $\mathrm{D}$ & Moderate & 80 & 1.3 & $\begin{array}{l}1 \mathrm{q}, 7 \mathrm{p}, 7 \mathrm{q}, 8 \mathrm{q}, 9 \mathrm{p}, 9 \mathrm{q}, 12 \mathrm{p} \\
12 \mathrm{q}, 13 \mathrm{q}, 20 \mathrm{q}, 21 \mathrm{q}\end{array}$ & $3 p, 4 p, 4 q, 8 p, 11 q, 18 q$ & 17 \\
\hline 22 & 84 & $\mathrm{~F}$ & Sigmoid & B2 & Moderate & 35 & 1.0 & $1 \mathrm{q}, 3 \mathrm{p}, 7 \mathrm{p}, 7 \mathrm{q}, 8 \mathrm{q}, 11 \mathrm{q}, 13 \mathrm{q}$ & $10 p, 19 p, 19 q$ & 10 \\
\hline 23 & 91 & $\mathrm{~F}$ & Rectum & B1 & Moderate & 52 & 1.0 & $\begin{array}{l}1 \mathrm{q}, 7 \mathrm{p}, 13 \mathrm{q}, 20 \mathrm{p}, 20 \mathrm{q}, 21 \mathrm{q} \\
22 \mathrm{q}, \mathrm{Xp}, \mathrm{Xq}\end{array}$ & $1 p, 2 p, 6 p, 16 p, 18 q$ & 14 \\
\hline
\end{tabular}

Histological type (for adenomas): T, tubular; V, villous. Stage (for carcinomas): Astler-Coller stage. Grade of dysplasia (adenomas): mild, moderate, severe. Grade of differentiation (carcinomas): well, moderate, poor.

found in hereditary non-polyposis colorectal cancer where a failing DNA mismatch repair system gives rise to replication errors (RER) which can be visualised as microsatellite instability (MIN); second, genomic instability caused by chromosomal copy number and structural changes affecting large parts and often complete arms of chromosomes. The latter process, which eventually gives rise to DNA aneuploidy, appears to be the cause of genomic instability in the vast majority of colorectal cancers and other solid tumours. ${ }^{34}$ Various hereditary syndromes exist in which an increased sensitivity to agents causing chromosomal breakage is associated with an increased tumour incidence. Nevertheless, no clear mechanism has yet been found to explain chromosomal instability in the majority of sporadic tumours in general, or colorectal cancer in particular. $^{56}$

The opportunities of analysing the magnitude and patterns of chromosomal instability in colorectal carcinogenesis have been greatly expanded by the recent development of comparative genomic hybridisation (CGH). This technique uniquely allows the detection of chromosomal gains (for example, trisomies and gene amplifications) and losses (monosomies and deletions) using only a small amount of tumour material, without the need for cell culturing, and it provides an overview of genomic changes at the chromosomal level in a tumour. ${ }^{78}$ In this procedure (fig 1), DNA isolated from tumour specimens is labelled with a green fluorochrome and mixed with red labelled DNA obtained from cells with a normal diploid chromosome complement. The mixture is hybridised to normal metaphase preparations. Hybridised test and control DNA sequences compete in the annealing process for their complementary sites on the individual chromosomes, and are recognised by the different fluorochromes. The ratio of green to red fluorescence for each chromosomal region is a measure of the under- or overrepresentation of genetic material for that region in the tumour studied. The relative copy number karyotype of a tumour, based on the analysis of multiple metaphases, gives an overview of chromosomal gains and losses in that tumour (fig 2). In this study, chromosomal gains and losses were surveyed by comparative genomic hybridisation in a series of colorectal adenomas and carcinomas, in search of high risk genomic changes involved in colorectal carcinogenesis.

\section{Methods}

TISSUE SAMPLES

Nine consecutive colorectal adenomas and 14 colorectal carcinomas (13 primary tumours and one liver metastasis) were used in the study. Patient and tumour characteristics are given in table 1. For $\mathrm{CGH}$, special care was taken to avoid admixture of stromal, blood, and non-tumour epithelial cells by brushing the surface of the tumour with cyto-brushes. Fresh tumour specimens were sampled within one hour of surgical resection. The brushes containing tumour cells were collected in phosphate buffered saline (PBS). The cells were removed from the brushes by pipetting with PBS using a Pasteur pipette, transferred to a new tube, and washed in PBS. The yield was estimated using a Buchner cell counter. In all cases adequate numbers of cells for CGH analysis (200 000 to 5000000 ) were obtained from the brushings. In addition to the cytological samples obtained from primary tumours, in one case material from a liver metastasis of a colorectal cancer was used. DNA was extracted using a QiAmp isolation kit (Qiagen $\mathrm{GmbH}$ ). 


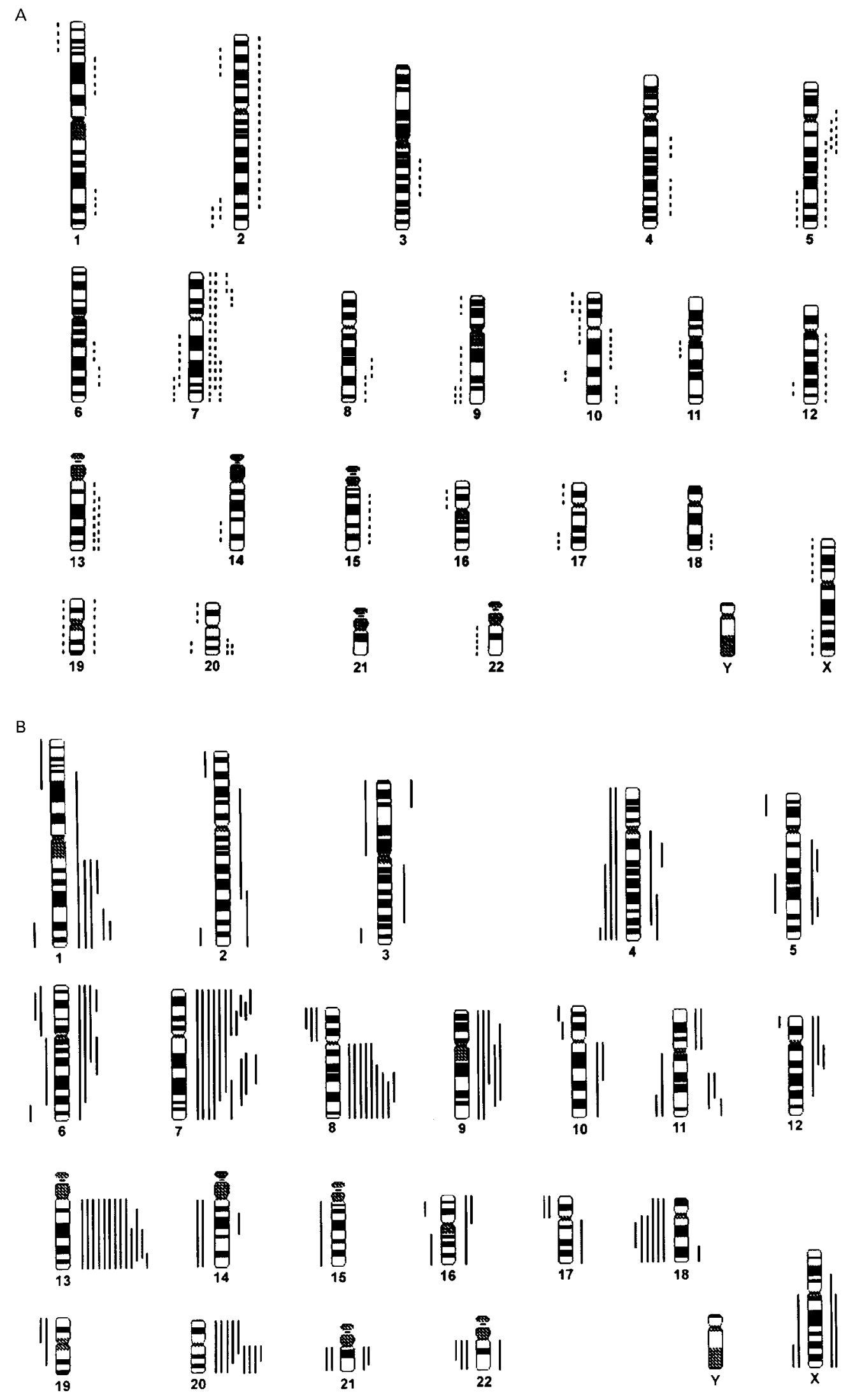

Figure 3 Frequency distribution of gains and losses of chromosomal material detected by comparative genomic hybridisation $(C G H)$ in nine adenomas $(A)$ and 14 carcinomas $(B)$ of the colorectum. Lines left of each chromosome represent losses, and lines on the right represent gains. 
Table 2 Mean number (and range) of chromosomal gains, losses and total number of events per tumour in nine colorectal adenomas and 14 colorectal carcinomas, as detected by comparative genomic hybridisation, and the $p$ values from the Mann-Whitney $U$ test for the significance of differences between the groups

\begin{tabular}{lllllll}
\hline & \multicolumn{2}{l}{$\begin{array}{l}\text { Adenomas } \\
(n=9)\end{array}$} & & \multicolumn{2}{l}{$\begin{array}{l}\text { Carcinomas } \\
(n=14)\end{array}$} \\
\cline { 2 - 3 } & Mean & Range & & Mean & Range & p Value \\
\hline Gains & 3.6 & 0 to 7 & & 8.2 & 2 to 16 & 0.003 \\
Losses & 3.0 & 0 to 8 & & 3.7 & 1 to 8 & NS \\
Events & 6.6 & 1 to 11 & & 11.9 & 5 to 17 & 0.008 \\
\hline
\end{tabular}

All samples were analysed by $\mathrm{CGH}$, and DNA ploidy was assessed in all cases using flow cytometry. Additional automated image cytometry was applied to cases that appeared diploid by flow cytometry, because the former is more sensitive for detecting small aneuploid cell populations. For the purpose of DNA cytometry, formaldehyde fixed, paraffin embedded material was used.

Histological type and grade of dysplasia of the adenomas were classified by one observer (GAM) according to generally accepted criteria. $^{9}{ }^{10}$

COMPARATIVE GENOMIC HYBRIDISATION

The CGH procedure is summarised in fig 1 . One microgram each of tumour and of reference DNA were labelled by nick translation with biotin-16-dUTP and digoxygenin11-dUTP (Boehringer Mannheim), respectively. Normal metaphase slides were prepared from PHA (phytohaemaglutinin) stimulated peripheral blood lymphocyte cultures from a healthy individual using standard procedures.

A $150 \mu \mathrm{g}$ sample of both tumour and reference labelled DNA was mixed with 100 times the same amount of human Cot-1 DNA (Boehringer Mannheim), precipitated, and dissolved in $10 \mu \mathrm{l}$ of hybridisation mix containing $50 \%$ formamide and $10 \%$ dextran sulphate in $2 \times$ SCC $(0.3 \mathrm{M}$ sodium chloride $/ 0.03 \mathrm{M}$ sodium citrate) ( $\mathrm{pH} 7$ ). The Cot-1 DNA was added to block highly polymorphic repeat sequences. The probes and the normal metaphase slides were denatured simultaneously for 22 seconds in a $130 \mathrm{~kW}$ Phillips microwave

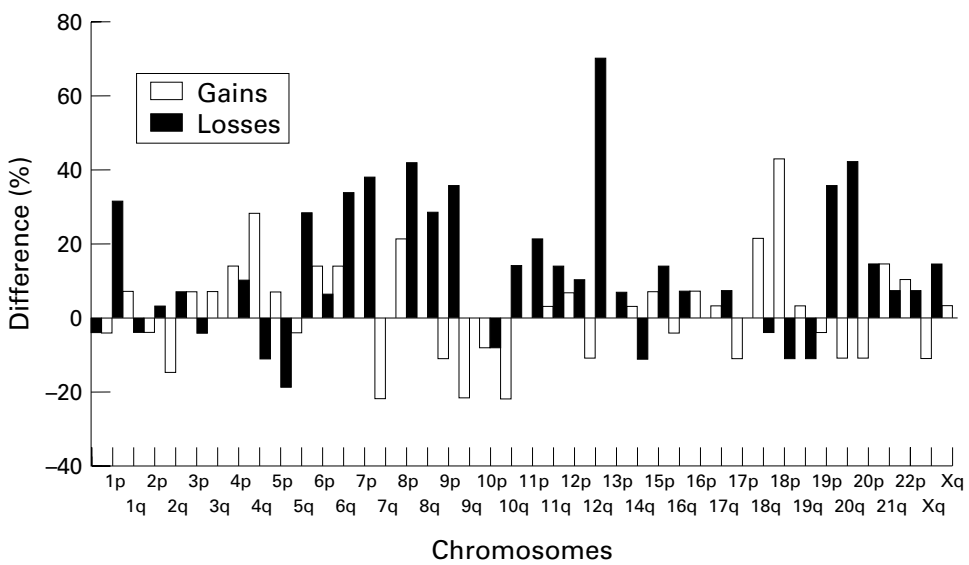

Figure 4 Differences in incidence of chromosomal gains and losses (\%) between nine colorectal adenomas and 14 carcinomas. For example, a gain of $13 q$ occurred in $22 \%$ of the adenomas and in $93 \%$ of the carcinomas, so a difference of $71 \%$ is displayed in the graph. Negative figures refer to events with a higher incidence in adenomas than carcinomas. This never exceeds $\sim 15 \%$ and thus may mark the level of background noise. oven at $60 \%$ power. ${ }^{11}$ The hybridisation took place in a humid incubator at $37^{\circ} \mathrm{C}$ for at least four days.

After hybridisation, the slides were washed three times for five minutes in $50 \%$ formamide $/ 2 \times \mathrm{NaCl} /$ sodium citrate (SSC) at $45^{\circ} \mathrm{C}$, two times for five minutes in $2 \times \mathrm{SSC}$ at $45^{\circ} \mathrm{C}$, and once for five minutes in TNT $(100$ $\mathrm{mM}$ Tris- $\mathrm{HCl}$ (pH 7.6), $150 \mathrm{mM} \mathrm{NaCl}, 0.05 \%$ Tween-20). The slides were then preincubated for 10 minutes at $37^{\circ} \mathrm{C}$ in blocking solution $(0.5 \%$ blocking agent (Boehringer) dissolved in TNT), followed by a 60 minute incubation at $37^{\circ} \mathrm{C}$ with $12.5 \mu \mathrm{g} / \mathrm{ml}$ FITC (fluorescein isothiocyanate) conjugated avidin (Sigma) and $4 \mu \mathrm{g} / \mathrm{ml}$ TRITC (tetraethylrhodamin isothiocyanate) conjugated sheep antidigoxygenin (Boehringer Mannheim) in blocking solution. The slides were washed three times for five minutes in TNT and counterstained with $200 \mathrm{ng} / \mathrm{ml}$ DAPI (4,6-di-amino-2-phenylindole) in $2 \times$ SCC. Finally, the slides were washed in $2 \times$ SSC for five minutes, dehydrated in an ethanol series of increasing concentration, and sealed in $10 \mu \mathrm{l}$ antifade solution (Vectashield, Vector Laboratories).

IMAGE ACQUISITION AND ANALYSIS

Using a Zeiss Axioskop fluorescence microscope equipped with three separate band pass filters (for DAPI, FITC and TRITC, respectively) and a CCD (charge coupled device) camera (Cohu 4913, Cohu Inc), separate DAPI, TRITC, and FITC digital images were recorded from each metaphase. Interactive karyotyping of the chromosomes and calculation of the green to red fluorescence ratio of each chromosome was performed with the Cytovision CGH software package (Applied Imaging). For the chromosomes of 5-10 well selected metaphases, the averaged fluorescence ratios and their $95 \%$ confidence intervals (CI) were plotted along ideograms of the corresponding chromosomes in a so called relative copy number karyotype. Deviations from normal were interpreted as gains or losses when the $95 \% \mathrm{CI}$ of the fluorescence ratio did not contain 1.0. An event was defined as gain or loss of (part of) a chromosomal arm. Results were validated by fluorescence in situ hybridisation with centromere specific probes on cytological preparations of the tumours.

DNA CYTOMETRY

Single cell suspensions for DNA ploidy analysis were prepared from all tumours using $50 \mu \mathrm{m}$ thick sections cut from the routinely processed, $4 \%$ buffered, formaldehyde fixed and paraffin embedded tissue. ${ }^{12}$ Tissue blocks with the highest concentrations of tumour were selected. The cell suspensions were divided for the purpose of both DNA flow cytometry and DNA automated image cytometry. The single cell suspensions for DNA flow cytometry were stained with DAPI and analysed with a PAS II (Partec Instruments) mercury lamp flow cytometer.

Cytospin preparations for DNA automated image cytometry were prepared from the cell suspensions by cytocentrifugation of $1 \mathrm{ml}$ of suspension onto a glass slide for five minutes at 


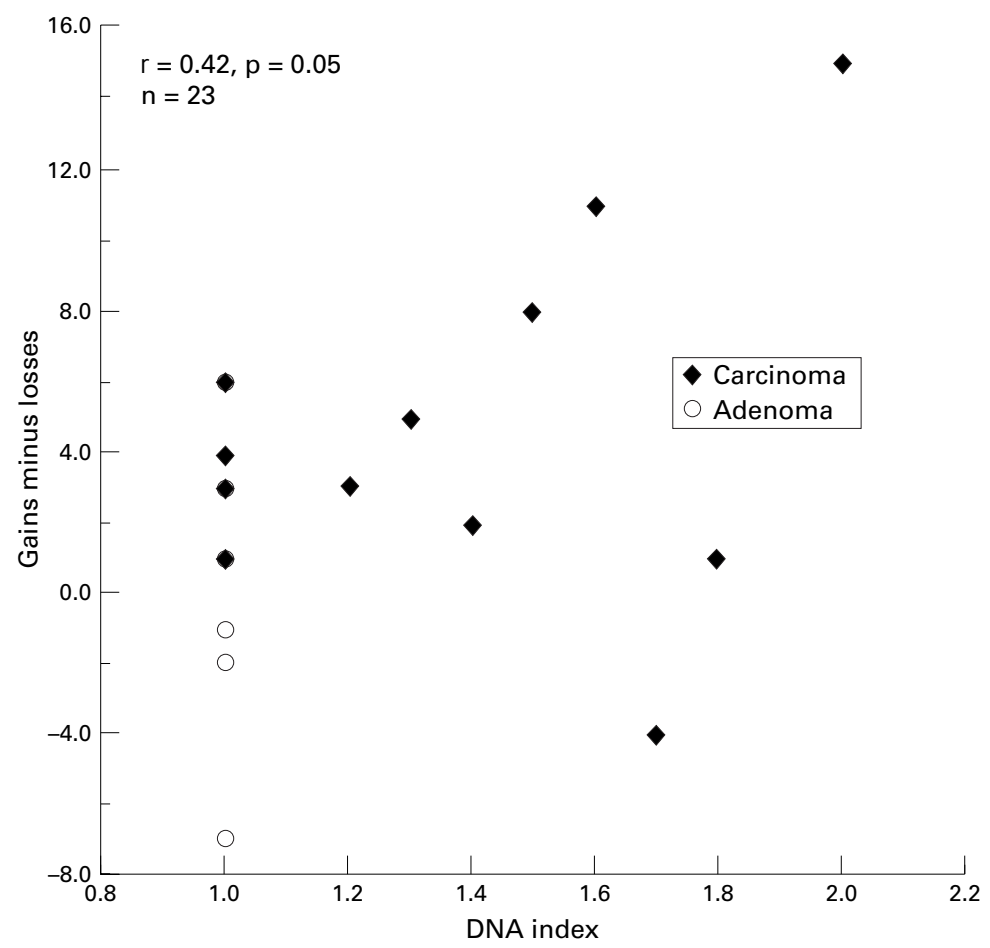

Figure 5 Correlation between the DNA index, assessed by DNA cytometry, and the number of gains minus the number of losses per tumour, as detected by comparative genomic hybridisation, in nine colorectal adenomas and 14 carcinomas.

$1000 \mathrm{rpm}$ and stained according to the (para-rosaniline) Feulgen procedure. ${ }^{13}$ For DNA automated image cytometry, the pathology image processing environment (PIPE) system was used. ${ }^{14}$ The PIPE system consists of a Zeiss Axioplan microscope equipped with an autofocus device, automated scanning stage, a Sony XC-77-CE CCD camera, and laboratory made dedicated software based on the SCIL Image (DIFA) image processing software. After shading correction and automatic segmentation, DNA content of at least 1000 (up to 4000) nuclei was automatically measured, based on the integrated optical density. ${ }^{14}$ DNA histograms were analysed using the MultiCycle (Phoenix Flow Systems) cell cycle analysis
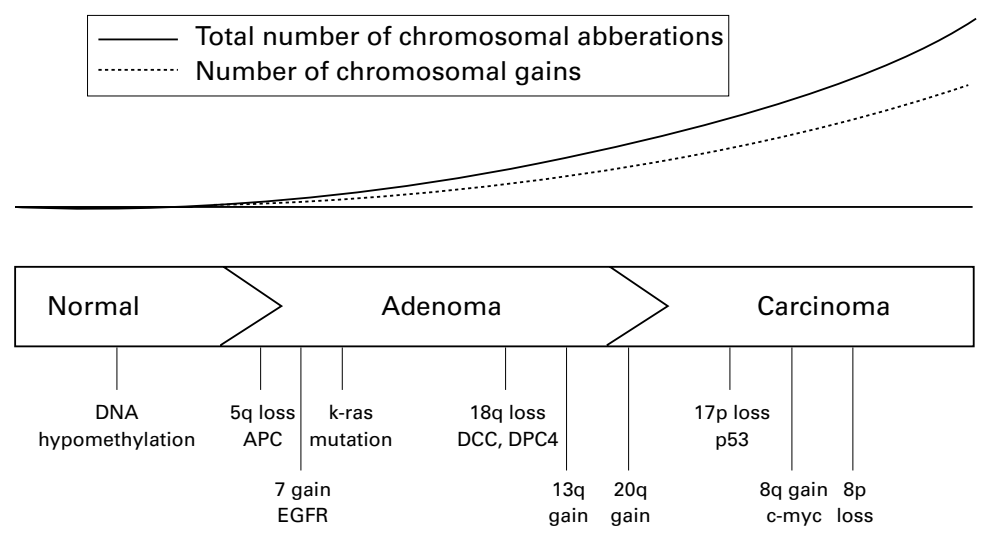

Figure 6 A model of chromosomal aberrations and possible candidate genes involved in the pathogenesis of colorectal cancer. In addition to the classical events (DNA hypomethylation, loss of $5 q / A P C, k$-ras mutation, loss of $18 q / D C C, D P C 4$, and $17 p / p 53)$, comparative genomic hybridisation and cytogenetic studies have pointed at the role of a gain of chromosome 7/EGFR, 13q, 20, and 8q/c-myc and a loss of 8p. Furthermore, the number of chromosomal aberrations increases with progression of neoplasia, and the number of gains is consistently higher than the number of losses. software. The DNA index was determined as the ratio of the modal DNA value of the second G0/G1 phase peak to the modal DNA value of the first G0/G1 phase peak in the DNA histogram. If only one $\mathrm{G} 0 / \mathrm{G} 1$ phase peak was present, a DNA index of 1.0 was assigned.

\section{STATISTICS}

For continuous variables, means and ranges were computed. Means of continuous variables in different groups were compared using the Mann-Whitney U test. Correlations were analysed with Pearson's coefficient of correlation. Differences in incidences of gains or losses between adenomas and carcinomas were analysed using Pearson's $\chi^{2}$. Probability ( $p$ ) values $<0.05$ were regarded as significant. All analyses were performed using the SPSS statistical software (SPSS Inc).

\section{Results}

Results for individual tumours are listed in table 1 and a frequency distribution of chromosomal gains and losses for adenomas and carcinomas is shown in fig 3. Overall, gains appeared more frequent than losses. The level of gains was mostly in the range of one to two extra copies (low level). Both gains and losses often involved large parts of, or even complete chromosome arms (fig 3).

Analysis of the 14 carcinomas revealed a significantly larger number of chromosomal events than in the nine adenomas (11.9 (5 to 17) $v 6.6$ ( 1 to 11$), \mathrm{p}=0.008)$, as shown in table 2 . While the number of losses did not differ significantly between carcinomas and adenomas (3.7 (1 to 8) and 3.0 (0 to 8), respectively), there was an increased number of gains 
in the carcinomas compared with the adenomas (8.2 (2 to 16) $v 3.6$ (range 0 to 7 ), $\mathrm{p}=0.003)$ ). In the adenomas, gains occurred most often at $7 \mathrm{p}, 7 \mathrm{q}$, and $5 \mathrm{q}$, and no chromosome showing more than two losses occurred in this series (fig 3A). In the carcinomas, gains were seen most often at $13 \mathrm{q}, 7 \mathrm{p}, 7 \mathrm{q}, 8 \mathrm{q}$, and 20q. Most frequent losses in the carcinomas occurred at $18 \mathrm{q}, 4 \mathrm{q}, 8 \mathrm{p}$, and $18 \mathrm{p}$ (fig $3 \mathrm{~B}$ ). The differences between adenomas and carcinomas in incidence of chromosomal gains and losses are shown in fig 4 . Most prominent was a $71 \%$ higher incidence of $13 \mathrm{q}$ gain in carcinomas compared with adenomas $(\mathrm{p}=0.0005)$, while for $8 \mathrm{q}$ gain, $20 \mathrm{q}$ gain, and $18 \mathrm{q}$ loss this difference was $42 \%(\mathrm{p}=0.05, \mathrm{p}=0.05$, and $\mathrm{p}=0.02$, respectively).

A clear association between the CGH results and DNA ploidy of the tumours was seen. The total number of events per tumour detected by CGH showed a significant positive correlation with DNA index assessed by DNA cytometry $(r=0.61, \mathrm{p}=0.001)$. Overall, DNA aneuploid tumours showed more gains than losses (mean $9.3 v 4.9, \mathrm{p}=0.02)$, in contrast with DNA diploid tumours (mean $3.1 v 4.1, \mathrm{p}=0.5$ ), and DNA index showed a significant positive correlation with the difference between gains and losses in each tumour (fig 5).

\section{Discussion}

The most striking difference in chromosomal aberrations between colorectal adenomas and carcinomas, as detected by CGH, is an increase in the number of (low level) gains. The meaning of this observation in terms of tumour biology is not yet clear. The Knudson model of tumour suppressor gene inactivation provides a clue to explain the biological meaning of losses. ${ }^{15}$ While high level gains often are associated with overexpression of oncogenes, the role of low level gains is not yet defined. However, this should be no reason to neglect these observations. One might argue that this increased incidence of gains of chromosomal material is merely the reflection of increased genomic instability. However, the fact that these gains show a non-random distribution favours the hypothesis that certain specific events like a gain of $13 \mathrm{q}$ especially, and also gains of $8 \mathrm{q}$ and $20 \mathrm{q}$, provide a growth advantage to tumour subclones experiencing these events. As these gains are much more prevalent in carcinomas than in adenomas, they could be critical in the progression of premalignant adenomas to invasive carcinomas. Alternatively, the gains might not be important in themselves, but merely reflect a process that has concurrently caused chromosomal loss. Gain of 8q, for example, was often associated with loss of $8 \mathrm{p}$, possibly because of isochromosome formation. Indeed studies on loss of heterozygosity have pointed to chromosome $8 \mathrm{p}$ as a site for putative tumour suppressor genes involved in colorectal cancer. ${ }^{16-18}$ However, for acrocentric chromosomes like chromosome 13, isochromosome formation of the long arm is not likely to cause loss of tumour suppressor genes since these chromosomes do not have a functional $\mathrm{p}$ arm. Another explanation could therefore be that certain oncogenes already show a biologically relevant increase of expression with a gain of only one or two copies. ${ }^{19}$ Increased expression in colorectal tumours of both epidermal growth factor receptor (EGFR) on $7 p$ and c-myc on $8 q$ support the importance of chromosomal gains in these tumours, and CGH studies of breast cancers have pointed at $20 \mathrm{q} 13$ as the site for an important oncogene. ${ }^{20}{ }^{21}$ Recently, gain of $20 \mathrm{q} 13$ was found to be associated with immortalisation in human papillomavirus transformed uroepithelial cells. ${ }^{22}$ Less straightforward options must also be considered. For instance, with respect to $13 \mathrm{q}$ both amplification and increased expression of the retinoblastoma gene have been reported in colorectal carcinomas, while in general one prefers to think that loss of $\mathrm{Rb}$ is the event that counts since it is a well known tumour suppressor gene. ${ }^{23} 24$

Gains may not be sufficient for progression to malignancy. In colorectal cancer loss of $18 \mathrm{q}$, where the DCC gene is located, is also a major event at this stage of tumour progression. In the present study $18 \mathrm{q}$ loss was the most prominent loss detected, showing a clear rise in incidence in carcinomas as compared with adenomas. One would also expect loss of p53 function to play a role, and although loss of $17 \mathrm{p}$ was seen with $\mathrm{CGH}$ in some carcinomas, the incidence was lower than would be expected. This may mean that loss of p53 function occurred by mutations (which cannot be detected by $\mathrm{CGH}$ ), or by small deletions which are below the detection threshold of CGH.

In the present study, loss of $5 \mathrm{q}$ was an infrequent finding. This may seem surprising considering the crucial role that loss of the APC tumour suppressor function on $5 \mathrm{q}$ is purported to play early in the adenoma-carcinoma sequence. However, this low frequency of $5 \mathrm{q}$ loss is consistently found in several CGH and cytogenetic studies of both colorectal adenomas and carcinomas. ${ }^{192526}$ Some studies have not found any loss of $5 \mathrm{q}$ at all. ${ }^{27}{ }^{28}$ This could mean that inactivation of APC would mainly occur at a subchromosomal level (for example, mutations or microdeletions), or that the incidence of loss of APC function is lower in some series of colorectal tumours than is currently thought. This issue requires further investigation.

It is known that CGH has some limitations in detecting aberrations at certain chromosomal regions with a high concentration of repetitive DNA sequences like 1p34-36, 16p, and chromosome 19, the profile rations of which should be interpreted with care. ${ }^{29}$ Since 1p34-36 has been reported to be commonly involved in colorectal tumours, ${ }^{30}$ additional techniques like in situ hybridisation with target specific probes may be needed to obtain unequivocal information for this region. ${ }^{31}$

In our present study most gains and losses detected appeared to involve major parts of chromosomes and often whole chromosome arms. This could indicate that (peri) centromeric breakage is an important event in the pathogenesis of these tumours, as has previ- 
ously been described for head and neck tumours. ${ }^{4}$

The results of our study are not isolated observations. However, comparison of the present data with those of other studies of genomic changes in colorectal cancer should be undertaken only with care. $\mathrm{CGH}$ is a powerful tool which provides the possibility of obtaining an overview of changes in chromosomal copy number in tumour material, without the need for cell culturing, thus enabling the analysis of chromosomal instability in a given tumour. This feature distinguishes CGH from other more "single target" molecular genetic techniques like FISH and loss of heterozygosity analysis, and in this respect CGH is only comparable with karyotyping. The latter, however, does require cell culturing, and although it has the additional advantage of detecting structural chromosomal changes, this prerequisite makes it difficult to apply in the "routine" pathology laboratory. As discussed elsewhere in more detail, these techniques should therefore be regarded as complementary and the one cannot be used unconditionally as a control for the other. ${ }^{32}$

CGH results can to some extent be compared with results of karyotyping, although here selection during cell culturing can occur. Probably the best control of $\mathrm{CGH}$ results should come from independent studies. Our present study provides the second series of colorectal adenomas and carcinomas analysed by $\mathrm{CGH}$, and when the results are compared with those of the first series of colorectal adenomas and carcinomas analysed by $\mathrm{CGH}$, the agreement in chromosomal aberrations detected indeed is striking. ${ }^{19}$ As in the present study, frequent gains were found at $13 q, 7 p$ and $\mathrm{q}, 8 \mathrm{q}$, and $20 \mathrm{q}$, whereas losses most often occurred at $18 \mathrm{q}$, and also at $4 \mathrm{q}, 8 \mathrm{p}$, and $18 \mathrm{p}$. Another study yielded similar CGH results in colorectal carcinomas, but no adenomas were analysed and the assessment of fluorescence ratios was primarily performed subjectively. ${ }^{25}$ In addition, the results in these CGH studies are in overall agreement with cytogenetic studies of large series of colorectal tumours, which found non-random gains at chromosome arms $7 \mathrm{p}, 7 \mathrm{q}, 8 \mathrm{q}, 13 \mathrm{q}$, and $20 \mathrm{q}$, and losses at $8 \mathrm{p}, 17 \mathrm{p}$, $18 \mathrm{p}$, and $18 \mathrm{q} .{ }^{26}{ }^{33}$ This certainly strengthens the impact of these CGH observations.

The results of DNA cytometry are in agreement with the $\mathrm{CGH}$ findings, further strengthening their import. In the DNA diploid tumours in this study (including all the adenomas), the number of gains and losses did not differ significantly, whereas DNA aneuploid tumours showed more gains than losses, thus explaining the increased DNA index. The fact that all DNA diploid tumours already showed chromosomal aberrations is in agreement with the observation that genomic instability is not caused by aneuploidy, but most probably precedes it. ${ }^{3}$ Still, some of the tumours that were DNA diploid in our present study could have shown DNA aneuploidy if fresh material had been available. Aneuploid adenomas most often show rather low DNA indices, which can more easily be detected in fresh samples than in formaldehyde fixed, paraffin embedded samples, like the ones that had to be used in this study. In addition, most adenomas showed mild or moderate dysplasia only with tubular histology (table 1), while DNA aneuploidy is more prevalent in adenomas with severe dysplasia. ${ }^{34}$

Current ideas on the genomic changes involved in colorectal carcinogenesis have been mainly based on the model proposed by Fearon and Vogelstein. ${ }^{1}$ However, CGH studies including the present study, and cytogenetic studies of colorectal tumours, have provided interesting additional information with respect to the genetic changes associated with colorectal cancer. In addition to the events outlined in Vogelstein's model, other chromosomal changesand especially gains of $7,8 \mathrm{q}, 13 \mathrm{q}$, and $20 \mathrm{q}$ - consistently appear to play a role in the genesis of colorectal carcinoma. Cytogenetic studies had already suggested this, but CGH has shown that these gains occur at even higher frequencies. These studies have also provided information to map some of these events along the adenoma-carcinoma sequence. Gain of chromosome 7 commonly occurs in adenomas. ${ }^{1935}$ Gain of $13 \mathrm{q}$ is also found in a minority of adenomas $(22 \%$ in the present study), but it becomes the most frequent event in carcinomas ( $93 \%$ in the present study, figs 3 and 4), indicating that it might play an important role in the transition from adenoma to carcinoma. Gain of $8 \mathrm{q}$ and $20 \mathrm{q}$ also seem to occur with much higher frequency in carcinomas than in adenomas, indicating that they might be late events in the adenoma-carcinoma sequence. In the same way, cytogenetic studies of adenomas reported gain of chromosome 20 in only $17 \%$ and $8 \%$ of adenomas respectively. ${ }^{27}{ }^{28}$ Gain of $8 \mathrm{q}$ was also an infrequent event in cytogenetic studies of adenomas. ${ }^{27} 28$

Combining this information, putative additional genetic events can be mapped to the adenoma-carcinoma sequence model of colorectal carcinogenesis (fig 6). One should keep in mind however, that this model presents a general picture, while differences may occur between individual tumours, and multiple pathways towards colorectal cancer probably exist. ${ }^{36}$

We conclude that the most striking difference between chromosomal aberrations in colorectal adenomas and carcinomas, as detected by $\mathrm{CGH}$, is an increased number of chromosomal gains that show a non-random distribution. Gains, especially of $13 \mathrm{q}$ and also of $20 \mathrm{q}$ and $8 \mathrm{q}$, seem to be involved in the progression of adenomas to carcinomas, possibly because of low level overexpression of oncogenes at these loci.

This study was supported by grant VU97-1455 of the Dutch Cancer Association. Technical assistance of Mrs J Brugghe, Mr M Broeckaert, and Mrs I Weiss is gratefully acknowledged.

1 Fearon ER, Vogelstein B. A genetic model for colorectal tumorigenesis. Cell 1990;61:759-67.

2 Kinzler KW, Vogelstein B. Gatekeepers and caretakers. Nature 1997;386:761-3.

3 Lengauer C, Kinzler KW, Vogelstein B. Genetic instability in colorectal cancer. Nature 1997;386:623-7.

4 Hermsen MAJA, Joenje H, Arwert F, et al. Centromeric breakage as a major cause of cytogenetic abnormalities in 
oral squamous cell carcinoma. Genes Chromosomes Cancer 1996;15:1-9.

5 Joenje H, Mathew C, Gluckman E. Fanconi anaemia research: current status and prospects. Eur F Cancer 1995; 31A:268-72.

6 Pippard EC, Hall AJ, Barker DJ, et al. Cancer in homozygotes and heterozygotes of ataxia-telangiectasia and xeroderma pigmentosum in Britain. Cancer Res 1988;48:2929-32

7 Kallioniemi A, Kallioniemi OP, Sudar D, et al. Comparative genomic hybridization for molecular cytogenetic analysis of solid tumors. Science 1992;258:818-21.

8 du Manoir S, Speicher MR, Joos S, et al. Detection of complete and partial chromosome gains and losses by comparative genomic in situ hybridization. Hum Genet 1993;90:590-610

9 Morson BC, Sobin LH. Histologic typing of intestinal tumours. In: International histologic classification of tumours,
No 15. Geneva: World Health Organisation, 1976 .

10 Konishi F, Morson BC. Pathology of colorectal adenomas: a colonoscopic survey. $\mathcal{F}$ Clin Pathol 1982;35:830-41.

11 de Meulemeester M, Vink A, Jakobs M, et al. The application of microwave denaturation in comparative genomic hybridization. Genet Anal Biomed Eng 1996;13:129-33.

12 Hedley DW, Friedlander ML, Taylor IW, et al. Method for analysis of cellular DNA content of paraffin-embedded pathological material using flow cytometry. $\mathcal{f}$ Histochem Cytochem 1983;31:1333-5.

13 Bocking A, Giroud F, Reith A. Consensus report of the ESACP task force on standardization of diagnostic DNA image cytometry. European Society for Analytical Cellular Pathology. Anal Cell Pathol 1995;8:67-74.

14 Baak JPA, Meijer GA, Brinkhuis M, et al. Quantitative pathology of gynecologic tumours. In: Fox H, Wells M, eds. raines and Taylor. Obstetrical and gynecological pathology, 4th

ed, vol 2. New York: Churchill Livingstone, 1995:1333-69. Acad Sci USA 1993;90:10914-21.

16 van der Bosch K, Becker I, Savelyeva L, et al. Deletions in the short arm of chromosome 8 are present in up to $90 \%$ of the short arm of chromosome 8 are present in up to $90 \%$ of haman colorectal $1992 ; 5: 91-5$.

17 Fujiwara Y, Emi $M$, Ohata $\mathrm{H}$, et al. Evidence for the presence of two tumor suppressor genes on chromosome $8 \mathrm{p}$ for colorectal carcinoma. Cancer Res 1993;53:1172-4.

18 Yaremko ML, Wasylyshyn ML, Paulus KL, et al. Deletion mapping reveals two regions of chromosome 8 allele loss in colorectal carcinomas. Genes Chromosomes Cancer 1994;10 $1-6$.

19 Ried T, Knutzen R, Steinbeck R, et al. Comparative genomic hybridization reveals a specific pattern of chromosomal gains and losses during the genesis of colorectal tumors. Genes Chromosomes Cancer 1996;15:234-45.

20 Kallioniemi A, Kallioniemi OP, Piper J, et al. Detection and mapping of amplified DNA sequences in breast cancer by
comparative genomic hybridization. Proc Natl Acad Sci USA 1994;91:2156-60.
21 Tanner MM, Tirkkonen M, Kallioniemi A, et al. Increased copy number at $20 \mathrm{q} 13$ in breast cancer: defining the critical region and exclu

22 Savelieva E, Belair CD, Newton MA, et al. 20q gain associates with immortalization: 20q13.2 amplification correlates with genome instability in human papillomavirus 16 E7 transformed human uroepithelial cells. Oncogene 1997;14: 551-60.

23 Gope R, Christensen MA, Thorson A, et al. Increased expression of the retinoblastoma gene in human colorectal carcinomas relative to normal colonic mucosa. 7 Natl Cancer Inst 1990;82:310-14.

24 Meling GI, Lothe RA, Borresen AL, et al. Genetic alterations within the retinoblastoma locus in colorectal carcinomas. Relation to DNA ploidy pattern studied by flow cytometric analysis. Br f Cancer 1991;64:475-80.

25 Schlegel J, Stumm G, Scherthan H, et al. Comparative genomic in situ hybridization of colon carcinomas with genomic in situ hybridization of colon carcino

26 Bardi G, Sukhikh T, Pandis N, et al. Karyotypic characterization of colorectal adenocarcinomas. Genes Chromosomes Cancer 1995;12:97-109.

27 Longy M, Saura R, Dumas F, et al. Chromosome analysis of adenomatous polyps of the colon: possible existence of two differently evolving cytogenetic groups. Cancer Genet Cytogenet 1993;67:7-13.

28 Griffin CA, Lazar S, Hamilton SR, et al. Cytogenetic analysis of intestinal polyps in polyposis syndromes: comparison with sporadic colorectal adenomas. Cancer Genet Cytogenet 1993;67:14-20.

29 Kallioniemi OP, Kallioniemi A, Piper J, et al. Optimizing comparative genomic hybridization for analysis of DNA sequence copy number changes in solid tumors. Genes Chromosomes Cancer 1994;10:231-43.

30 Hanash SM. A role for chromosome 1 in colorectal cancer. Gastroenterology 1996;111:250-2.

31 Di Vinci A, Infusini E, Peveri C, et al. Deletions at chromosome $1 \mathrm{p}$ by fluorescence in situ hybridization are an early some $1 \mathrm{p}$ by fluorescence in situ hybridization are an early
event in human colorectal tumorigenesis. Gastroenterology 1996;111:102-7.

32 Hermsen MAJA, Meijer GA, Baak JPA, et al. Comparative genomic hybridization: a new tool in cancer pathology. Hum Pathol 1996;27:342-9.

33 Muleris M, Salmon RJ, Dutrillaux B. Cytogenetics of colorectal adenocarcinomas. Cancer Genet Cytogenet 1990;46: 143-56.

34 Goh HS, Jass JR. DNA content and the adenomacarcinoma sequence in the colorectum. F Clin Pathol 1986; 39:387-92.

35 Herbergs J, Hopman $\mathrm{AH}$, De Bruine $\mathrm{AP}$, et al. In situ hybridization and flow cytometric analysis of colorectal tumours suggests two routes of tumorigenesis characterized by gain of chromosome 7 or loss of chromosomes 17 and 18. F Pathol 1996;179:243-7.

36 Ilyas M, Tomlinson IPM. Genetic pathways in colorectal cancer. Histopathology 1996;28:389-99. 